\title{
Preemptive ganciclovir for mechanically ventilated patients with cytomegalovirus reactivation
}

\author{
Laurent Papazian ${ }^{*} \mathbb{0}$, Samir Jaber ${ }^{2}$, Sami Hraiech ${ }^{1}$, Karine Baumstarck ${ }^{3}$, Sophie Cayot-Constantin ${ }^{4}$, \\ Nadia Aissaoui ${ }^{5}$, Boris Jung ${ }^{6}$, Marc Leone ${ }^{7}$, Bertrand Souweine $^{8}$, Carole Schwebel $^{9}$, Jérémy Bourenne ${ }^{10}$, \\ Jérôme Allardet-Servent ${ }^{11}$, Toufik Kamel ${ }^{12}$, Qin Lu ${ }^{13}$, Christine Zandotti ${ }^{14}$, Anderson Loundou ${ }^{3}$, \\ Christine Penot-Ragon ${ }^{15}$, Jean Chastre ${ }^{16}$, Jean-Marie Forel ${ }^{1}$ and Charles-Edouard Luyt $^{16}$ on behalf of the \\ Preemptive Herpesviridae Treatment Study Group, REVA Network
}

\begin{abstract}
Background: The effect of cytomegalovirus (CMV) reactivation on the length of mechanical ventilation and mortality in immunocompetent ICU patients requiring invasive mechanical ventilation remains controversial. The main objective of this study was to determine whether preemptive intravenous ganciclovir increases the number of ventilatorfree days in patients with CMV blood reactivation.

Methods: This double-blind, placebo-controlled, randomized clinical trial involved 19 ICUs in France. Seventy-six adults $\geq 18$ years old who had been mechanically ventilated for at least $96 \mathrm{~h}$, expected to remain on mechanical ventilation for $\geq 48 \mathrm{~h}$, and exhibited reactivation of CMV in blood were enrolled between February 5th, 2014, and January 23rd, 2019. Participants were randomized to receive ganciclovir $5 \mathrm{mg} / \mathrm{kg}$ bid for 14 days $(n=39)$ or a matching placebo $(n=37)$.
\end{abstract}

Results: The primary endpoint was ventilator-free days from randomization to day 60. Prespecified secondary outcomes included day 60 mortality. The trial was stopped for futility based on the results of an interim analysis by the DSMB. The subdistribution hazard ratio for being alive and weaned from mechanical ventilation at day 60 for patients receiving ganciclovir $(N=39)$ compared with control patients $(N=37)$ was $1.14(95 \% \mathrm{Cl}$ from 0.63 to $2.06 ; P=0.66)$. The median $[\mathrm{IQR}]$ numbers of ventilator-free days for ganciclovir-treated patients and controls were 10 [0-51] and 0 [0-43] days, respectively $(P=0.46)$. Mortality at day 60 was $41 \%$ in patients in the ganciclovir group and $43 \%$ in the placebo group $(P=$.845). Creatinine levels and blood cells counts did not differ significantly between the two groups.

Conclusions: In patients mechanically ventilated for $\geq 96 \mathrm{~h}$ with CMV reactivation in blood, preemptive ganciclovir did not improve the outcome.

Keywords: Mechanical ventilation, Randomized, Clinical trial, Mortality, Immunocompetent

\footnotetext{
*Correspondence: laurent.papazian@ap-hm.fr

${ }^{1}$ Médecine Intensive Réanimation, Aix-Marseille Université, Hôpital Nord,

Chemin des Bourrely, 13015 Marseille, France

Full list of author information is available at the end of the article
}

\section{Introduction}

It is generally reported that 60 to $80 \%$ of immunocompetent adults are human cytomegalovirus (CMV) seropositive [1, 2]. Following primary infection (asymptomatic or with nonspecific signs and symptoms), CMV remains quiescent in monocytes and macrophages in multiple organs (latency). Due to immune status alterations, 
critically ill patients are at risk of reactivation [3]. A recent meta-analysis of 18 studies involving $2398 \mathrm{immu}$ nocompetent patients showed that $31 \%$ of intensive care unit (ICU) patients may experience CMV reactivation, regardless of the site (blood or lung) of reactivation [4]. CMV reactivation may cause injury by different mechanisms: by a direct cytopathologic effect in organs containing the virus, such as occurs during CMV pneumonia [5-7]; by an excessive immune response to the virus, such as what is hypothesized to happen in ARDS patients [8]; and/or by altering the immune response facilitating fungal and bacterial infections [9-12]. Regarding the proinflammatory properties of $\mathrm{CMV}$, it has been shown that CMV can enhance the progression of postaggressive lung fibrosis [13]. However, there is no convincing data to support the use of antiviral treatment when CMV is detected in non-immunocompromised critically ill patients. The pathogenicity of CMV in immunocompetent critically ill patients is also questionable because based on epidemiological noninterventional studies, reactivation might only be an indicator of immune response impairment and illness severity not necessitating diagnostic procedures and treatment. An interventional trial aiming to determine whether antiviral therapy is safe and effective for preventing CMV reactivation showed that valacyclovir or low-dose valganciclovir were able to decrease CMV reactivation in a general population of critically ill patients [14]. The duration of mechanical ventilation was not assessed, and increased mortality was reported for the valacyclovir group [14]. A multicenter double-blind, placebo-controlled, randomized clinical trial conducted in $160 \mathrm{CMV}$-seropositive adults with either sepsis or trauma and respiratory failure concluded that the prophylactic use of ganciclovir was able to reduce CMV reactivation and increase the number of ventilator-free days, but was unable to lower interleukin-6 levels (main objective) [15]. To reduce the number of patients receiving ganciclovir, which is a drug associated with some side effects, it would be of interest to limit the administration of this treatment to patients presenting reactivation without any sign of end-organ disease. The present study was therefore designed to assess whether preemptive ganciclovir is able to increase the number of ventilator-free days in patients with CMV reactivation in blood after at least 4 days of invasive mechanical ventilation.

\section{Materials and methods Study design}

This randomized, multicenter, double-blind, placebocontrolled trial was conducted in 19 ICUs in France (from February 5th, 2014, to January 23rd, 2019) (Trial registration-ClinicalTrials.gov Identifier NCT02152358). The sponsor was the Assistance Publique-Hôpitaux de Marseille, and a grant was obtained from the French Ministry of Health (PHRC 2011). An independent Ethics Committee (Comité de Protection des Personnes Sud Méditerranée 5) approved the protocol and the amendments. Study sites and investigators are listed in the Appendix. The trial protocol has already been published (Additional file 1) [16].

During the study period, potentially eligible patients (i.e., those under invasive mechanical ventilation for $\geq 96 \mathrm{~h}$ ) were screened twice weekly for CMV and herpesvirus simplex (HSV) reactivations, respectively, with quantitative or qualitative polymerase chain reactions (PCR) on whole blood or oropharyngeal swabs collected the same day for as long as the patients remained under invasive mechanical ventilation with a maximum of 30 days of mechanical ventilation. Patients with CMV blood reactivation or concomitant HSV oropharyngeal reactivation and CMV blood reactivation were eligible for the CMV trial, whereas patients with HSV oropharyngeal reactivation were eligible for the HSV trial. The results of the study related to HSV-positive patients (HSV trial) have been recently published [16]. We report here the results of the CMV trial. Once the patient was included in the trial, the systematic PCR results were no longer transmitted to the clinicians (unless the clinician specifically asked for them when there was a suspected active infection). Patients could not be included in another study. Patients and/or their relatives were informed of this screening until December 2015, when screening became routine care, and French law rendered informing them no longer necessary.

\section{Study participants}

Patients who were at least 18 years of age, had been mechanically ventilated for at least $96 \mathrm{~h}$ with a predicted mechanical ventilation duration longer than $48 \mathrm{~h}$, had CMV-positive whole blood and provided written informed consent from the patient or his/her legally authorized representative were eligible for enrollment. Finally, the patient's follow-up informed consent was obtained as soon as possible. Exclusion criteria were as follows: age $<18$ years; patients deprived of freedom or under legal protection; patients not covered by social security; use of acyclovir, ganciclovir or another antiviral with anti-HSV/CMV activity (e.g., cidofovir or foscarnet) at the time of randomization; patients with known hypersensitivity to ganciclovir; patients who had an active HSV or CMV infection treated during the preceding month; patients who were pregnant or lactating; patients with pancytopenia, neutropenia $\leq 500 / \mathrm{mm}^{3}$, or thrombocytopenia $<25 \mathrm{G} / \mathrm{L}$; patients with solid-organ or bone marrow transplants; patients on immunosuppressant therapy (including corticosteroids at $\geq 0.5 \mathrm{mg} / \mathrm{kg} / \mathrm{day}$ of 
prednisone or its equivalent for $>1$ month); patients with human immunodeficiency virus infection; patients with moribund conditions defined as a preinclusion Simplified Acute Physiology Score (SAPS) II $\geq 75$; patients regarding whom a decision had been made to withhold or withdraw life-sustaining treatment; and patients with an ICU readmission during the same hospital stay.

\section{DNAemia}

"DNAemia" was defined as the detection of CMV DNA in whole blood. The nucleic acid amplification techniques used in all sites were calibrated to a standard calibrator, which was the WHO International Standard for Human CMV [17]. A threshold set at $500 \mathrm{IU} / \mathrm{mL}$ whole blood was chosen as the inclusion criterion (close to the limit of detection at the time the study was designed).

\section{Randomization}

A centralized, secure, web-based, randomization system using minimization assigned patients at a 1:1 ratio, with stratification by study site, prerandomization invasive mechanical ventilation duration $(\leq 14$ or $>14$ days) and number of organ failure(s) split into 2 levels: $<2$ or $\geq 2$ organ failures according to the SeqSequential OrganFailure Assessment [18] (SOFA) score. A specific organ failure was defined by the corresponding SOFA score $>2$.

\section{Study interventions}

Patients were randomized to receive ganciclovir administered intravenously in $1 \mathrm{~h}$ at a dose of $5 \mathrm{mg} / \mathrm{kg}$ or a matching placebo (control group) preparation every $12 \mathrm{~h}$ for patients with normal renal function (creatinine $<120 \mu \mathrm{mol} / \mathrm{l}$ ) and for a maximum total duration of 14 days. For extubated patients discharged from the ICU before day 14 post-randomization, the study agent was stopped at discharge. Ganciclovir doses were adjusted to renal function according to the manufacturer's recommendations. Placebo and ganciclovir were conditioned in similar bottles that were distributed post-randomization and reconstituted in glucose solution by the nurses before each administration. By February 2016, 37 patients had been included, and the placebo-batch dates had surpassed the expiration. The independent Ethics Committee approved trial modification of the placeboand ganciclovir-distribution procedure. To maintain the blinded-study design for ICU personnel, the hospital pharmacy or a nurse from a different unit reconstituted and distributed ganciclovir- or placebo-containing glucose bags daily to ICU nurses treating the patients throughout the study period. Criteria to interrupt the ganciclovir treatment or its placebo were the presence of leukopenia $<1000 / \mathrm{mm}^{3}$ and/or neutropenia $\leq 500 / \mathrm{mm}^{3}$ and/or thrombocytopenia $<25 \mathrm{G} / \mathrm{L}$.

\section{Study outcomes}

The primary outcome was the number of ventilator-free days at day 60 (VFD60) from randomization, i.e., days alive and free from invasive mechanical ventilation [19]. For patients who died before day 60, that number was zero, regardless of invasive mechanical ventilation duration. For patients with multiple mechanical ventilation episodes during the 60-day follow-up period, days without invasive mechanical ventilation were considered only after the last weaning-off invasive mechanical ventilation. Secondary outcomes included the day-60 mortality rate; mechanical ventilation duration; occurrence of HSV bronchopneumonitis or active cytomegalovirus infection; secondary bacterial pneumonia, bacteremia or fungemia; incidence of acute respiratory distress syndrome (ARDS) and septic shock post-randomization. Active CMV infection was defined by the presence of an antigenemia $>10$ cells/200 000 cells and/or a positive qualitative PCR on BAL and/or the presence of IgM WITH associated clinical or biological symptoms (transaminases $>3$ times the norm) (digestive $=$ positive biopsy). The main safety endpoints were myelotoxicity and acute renal failure.

\section{Data safety monitoring board}

Safety oversight was under the direction of an independent Data Safety Monitoring Board (DSMB). The DSMB convened by teleconferencing or in person at $25 \%, 50 \%$ and $75 \%$ of enrollment to review adverse events or earlier if so needed. The DSMB might be questioned for other logistical, ethical, and clinical points.

\section{Statistical analysis}

According to a previous study evaluating Herpesviridae reactivation in patients with prolonged invasive mechanical ventilation, the expected standard deviation (SD) of ventilator-free days for controls was \pm 20 days [20]. We hypothesized that preemptive ganciclovir administration could increase the number of ventilator-free days by 8 days. To have $80 \%$ power with a $5 \%$ alpha level, 112 patients had to be included per group (after applying a correcting coefficient of 0.864 to adjust for asymptotic test efficiency). To account for potential losses to followup, that number was raised to 120 per group, meaning 240 patients had to be included. The statistical analysis plan specific to the CMV arm detailed all the scheduled methodological approach (Additional file 2).

The primary outcome was first analyzed according to the Fine \& Gray competitive risk model [21] (primary analysis), with death as the competitive risk. The results are presented as the subdistribution hazard ratio (SHR) and the 95\% confidence interval (95\% CI) effect size. Complementary results (secondary analyses) were 
provided for the primary outcome: (i) VFD60 median comparison between groups (Mann-Whitney test); (ii) hierarchical composite endpoint (alive and ventilator free) that considers death worse than prolonged ventilation and compares each patient with every other patient in a win-lose-tie for each comparison (Mann-Whitney test) [22-24].

Data are expressed as the median [interquartile range $(\mathrm{IQR})]$ or mean ( \pm standard deviation, $S D)$, as appropriate. Between-group comparisons used Student's t-test or the Mann-Whitney U-tests for continuous variables and $\chi^{2}$ or Fisher's exact tests for categorical variables. Censored outcomes (time to death and time to weaning-off mechanical ventilation) were described with the KaplanMeier method, with between-group log-rank-test comparisons. The main analyses were conducted on an intention-to-treat basis. All analyses were computed with IBM SPSS statistics 20, R software, version 3.5.1 (R Foundation) at a two-sided, $5 \%$ alpha level.

Non-prespecified metanalyses were finally performed for three endpoints taking into account two already published randomized clinical trials $[14,15]$ and the present one. Day 28 mortality and hospital mortality were analyzed using odd ratios $(95 \% \mathrm{CI})$, defined as the ratio of the probability of an event occurring between two groups. Ventilator-free days to day 28 were analyzed using standardized means difference (standard error), expressing the size of the intervention effect (means and standard deviations were estimated from the medians and interquartile ranges) [25, 26]. We used fixed effects [27] and random effects models [28], which account for the between-study heterogeneity by weighting studies similarly. Heterogeneity was assessed using the $\mathrm{I}^{2}$ statistic, which represents the percentage of variance due to between-study factors rather than to sampling error [29]. We considered values of $\mathrm{I}^{2}>50 \%$ as indicative of large heterogeneity.

\section{Results}

Due to a large gap between the theoretical and real inclusion curves and also the budget implications, the sponsor solicited the independent DSMB. The DSMB, in agreement with the sponsor, asked therefore to have results for the primary endpoint. Based on this report, the DSMB wanted unblinding to determine continuation or to stop the study. After breaking the randomization code, the DSMB recommended to stop the trial for futility after the interim analysis had concluded that at least 822 patients would have been necessary to show a difference between the two groups. The trial was therefore stopped on May 15th, 2019. Among the 2809 patients screened for HSV and cytomegalovirus, 76 were randomized (Fig. 1). There was no consent withdrawal, and all 76 patients remained in the analysis:

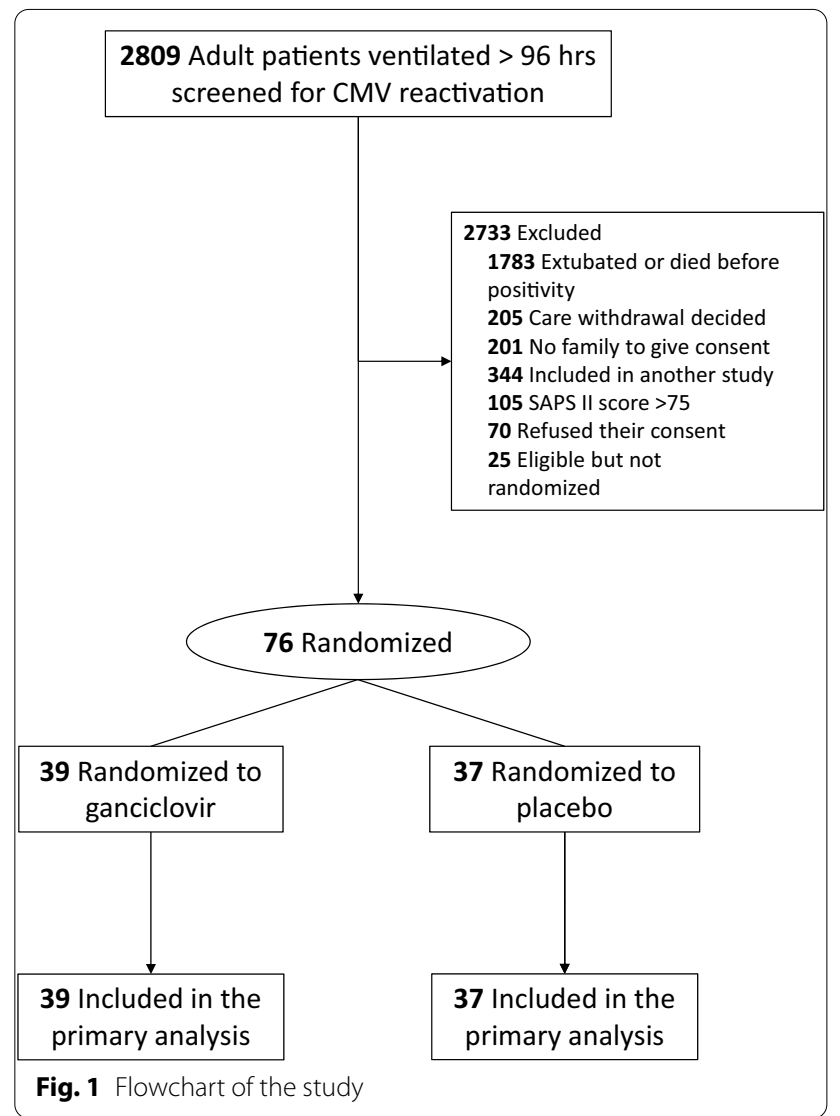

39 ganciclovir recipients and 37 placebo-treated controls. The baseline characteristics at ICU admission (Table 1) did not differ between the two groups. Their characteristics at randomization were also comparable (Table 2). The median [IQR] prerandomization duration of mechanical ventilation was 15.0 [10.0-22.0] days in the placebo group and 14.0 [9.0-22.0] days for the ganciclovir group $(P=0.925)$. The modified clinical pulmonary infection score at randomization was $5.8 \pm 2.3$ in the placebo group and $5.4 \pm 2.4$ in the ganciclovir group $(P=0.501)$. The median [IQR] quantity of CMV was 1760 [1031-3344] IU/ml in the placebo group compared with 1915 [1120-3105] IU/ml in the ganciclovir group $(P=0.763)$.

\section{Study drug}

All patients received at least one study-agent dose. The median [IQR] treatment durations were similar (Table 3). Thirty-nine patients (18 ganciclovir recipients and 21 controls) stopped the study agent earlier than scheduled. Reasons for discontinuation for ganciclovir recipients and controls were 16 deaths (9 and 7), 15 ICU discharges (8 and 7), one ganciclovir/placebo-related adverse event 
Table 1 Patient characteristics at ICU admission

\begin{tabular}{|c|c|c|}
\hline Characteristics & Placebo group $(N=37)$ & Ganciclovir group $(N=39)$ \\
\hline Age, $y$ & $67.0(59.0-72.0)$ & $63.0(54.0-71.0)$ \\
\hline Male sex, no. (\%) & $25(67.6)$ & $31(79.5)$ \\
\hline Body mass index, kg/mª & $27.7(21.3-31.2)$ & $26.2(23.6-35.2)$ \\
\hline McCabe score = 1 (non-fatal), no. (\%) & $32(86.5)$ & $28(71.8)$ \\
\hline \multicolumn{3}{|l|}{ Preexisting disease, no. (\%) } \\
\hline NYHA III/IV & $4(10.8)$ & $3(7.7)$ \\
\hline Cancer/hemopathy & $3(8.1)$ & $7(17.9)$ \\
\hline Diabetes mellitus & $6(16.2)$ & $10(25.6)$ \\
\hline COPD & $4(10.8)$ & 7 (17.9) \\
\hline Cirrhosis & $3(8.1)$ & $0(0)$ \\
\hline Chronic renal failure $^{a}$ & $1(2.7)$ & $2(5.1)$ \\
\hline Alcoholism, no. (\%) & $6(16.2)$ & $5(12.8)$ \\
\hline Recent transfusion (<1 month), no. (\%) & $12(32.4)$ & $13(33.3)$ \\
\hline Corticosteroids (<1 month), no. (\%) & $5(13.5)$ & $1(2.6)$ \\
\hline No preexisting disease and no risk factor, no. (\%) & $17(45.9)$ & $16(41)$ \\
\hline \multicolumn{3}{|l|}{ Admission category, no. (\%) } \\
\hline Medical & $31(83.8)$ & $34(87.2)$ \\
\hline Emergency surgery & $2(5.4)$ & $4(10.3)$ \\
\hline Planned surgery & $4(10.8)$ & $1(2.8)$ \\
\hline \multicolumn{3}{|l|}{ Primary reason for mechanical ventilation, no. (\%) } \\
\hline Acute respiratory failure & $13(35.1)$ & $12(30.8)$ \\
\hline Septic shock & $8(21.6)$ & $8(20.5)$ \\
\hline Cardiogenic shock & $2(5.4)$ & $5(12.8)$ \\
\hline Post-operative acute respiratory failure & $4(10.8)$ & $1(2.6)$ \\
\hline Exacerbation of chronic respiratory disease & $0(0)$ & $4(10.3)$ \\
\hline Trauma & $1(2.7)$ & $0(0)$ \\
\hline Neurologic & $1(2.7)$ & $1(2.6)$ \\
\hline Cardiac arrest & $1(2.7)$ & $0(0)$ \\
\hline Others & $7(18.9)$ & $8(20.5)$ \\
\hline SAPS $\|$ & $45.0(38.5-56.5)$ & $45.0(37.0-59.0)$ \\
\hline SOFA score & $10(8-15)$ & $9(7-10)$ \\
\hline \multicolumn{3}{|l|}{ Organ/system failure, no. (\%) } \\
\hline Cardiovascular & $23(62.2)$ & $28(71.8)$ \\
\hline Respiratory & $26(81.2)$ & $29(80.6)$ \\
\hline Renal & $11(29.7)$ & $11(28.2)$ \\
\hline Central nervous & $8(21.6)$ & $1(2.6)$ \\
\hline Hepatic & $1(2.8)$ & $2(5.3)$ \\
\hline Coagulation & $4(10.8)$ & $2(5.1)$ \\
\hline
\end{tabular}

Results are expressed as median (IQR) unless stated otherwise

NYHA denotes New York Heart Association, COPD chronic obstructive pulmonary disease, SAPS Simplified Acute Physiology Score, SOFA Sequential Organ-Failure Assessment

a Creatinine clearance $<60 \mathrm{ml} / \mathrm{min}$, creatinine $>150 \mu \mathrm{mol} /$ liter or chronic dialysis

b Organ/system failure was deemed present when the corresponding SOFA score was $>2$. When data regarding organ/system failure were missing, number of assessable patients is reported

(0 and 1), five cases of CMV reactivation/HSV bronchopneumonitis (4 and 1$)$, and two physicians' decisions (0 and 2).

\section{Primary endpoint}

The subdistribution hazard ratio for being alive and weaned from mechanical ventilation at day 60 after 
Table 2 Patient characteristics at randomization

\begin{tabular}{|c|c|c|}
\hline Characteristics & Placebo group $(N=37)$ & Ganciclovir group $(N=39$ \\
\hline Ongoing antimicrobial treatment, no. (\%) & $26(70.3)$ & $28(71.8)$ \\
\hline ECMO use, no. (\%) & $5(13.5)$ & $6(15.4)$ \\
\hline Renal replacement therapy, no. (\%) & $14(37.8)$ & $13(33.3)$ \\
\hline SOFA score & $8.0(5.0-11.0)$ & $8.5(4.0-10.3)$ \\
\hline \multicolumn{3}{|l|}{ Organ/system failure, no. (\%) ${ }^{a}$} \\
\hline Cardiovascular & 18 (48.6) & $19(48.7)$ \\
\hline Respiratory & $22(59.5)$ & $24(61.5)$ \\
\hline Renal & $12(32.4)$ & $14(35.9)$ \\
\hline Central nervous & $6(16.2)$ & $4(10.3)$ \\
\hline Hepatic & $2(5.4)$ & $3(7.9)$ \\
\hline Coagulation & $2(5.4)$ & $2(5.1)$ \\
\hline Body temperature, ${ }^{\circ} \mathrm{C}$ & $37.7(36.3-38.2)$ & $37.8(36.9-38.3)$ \\
\hline White blood-cell count, G/L & $13.6(10.2-17.8)$ & $14.0(10.2-20.0)$ \\
\hline Neutrophil count, G/L & $11.4(7.5-15.6)$ & $10.7(7.1-16.0)$ \\
\hline $\mathrm{PaO}_{2} / \mathrm{FiO}_{2}, \mathrm{mmHg}$ & $175.0(127.5-237.0)$ & $170.0(111.0-240.0)$ \\
\hline Radiologic score & $6.0(4.0-8.5)$ & $5.5(3.0-8.0)$ \\
\hline Tidal volume, $\mathrm{mL}$ & $450.0(390.3-554.3)$ & $448.0(370.5-497.0)$ \\
\hline Respiratory rate, cycles/min & $28.0(20.0-33.0)$ & $25.0(22.0-29.3)$ \\
\hline Minute ventilation, L/min & $12.0(9.2-14.9)$ & $10.4(8.7-13.9)$ \\
\hline PEEP, $\mathrm{cmH} 2 \mathrm{O}$ & $8.0(5.0-10.0)$ & $8.0(6.0-12.0)$ \\
\hline Plateau pressure, $\mathrm{cmH} 2 \mathrm{O}$ & $19.0(15.0-26.0)$ & $22.0(17.3-26.5)$ \\
\hline $\mathrm{FiO}_{2}, \%$ & $40.0(30.0-50.0)$ & $40.0(35.0-55.0)$ \\
\hline $\mathrm{pH}$ & $7.43(7.36-7.48)$ & $7,42(7.37-7.48)$ \\
\hline $\mathrm{PaO}_{2}, \mathrm{mmHg}$ & $85.0(70.5-102.0)$ & $81.0(67.5-115.0)$ \\
\hline $\mathrm{PaCO}_{2}, \mathrm{mmHg}$ & $35.0(33.0-41.0)$ & $40.5(35.0-45.3)$ \\
\hline
\end{tabular}

Results are expressed as median (IQR) unless stated otherwise

There were no significant between-group differences in characteristics at randomization

MV denotes mechanical ventilation, ECMO extracorporeal membrane oxygenation, $\mathrm{SOFA}$ Sequential Organ- $\mathrm{Failure} \mathrm{Assessment}_{1} \mathrm{PaO}_{2} / \mathrm{FiO}_{2}$ partial oxygen pressure in arterial blood/fraction of inspired oxygen ratio

a Organ/system failure was deemed present when the corresponding SOFA score was $>2$

randomization in patients receiving ganciclovir compared with control patients was 1.14 (95\% CI from 0.63 to $2.06 ; P=0.66)$ in the primary analysis. The median [IQR] numbers of VFD60 after randomization for ganciclovirtreated patients and controls were $10[0-51]$ and $0[0-43]$ days, respectively $(P=0.46)$. Hierarchical composite endpoint (alive and ventilation free) using the alternative technique to compare VFD60 (Finkelstein method [23]) did not result in a significant between-group difference $(P=0.524)$. The post hoc power of the final analysis of the primary endpoint was $14.2 \%$.

\section{Secondary endpoints}

As shown in Table 3 and in Fig. 2a, there was no difference between the two groups regarding mortality evaluated at day 60 after randomization. All patients died in the ICU after a median [IQR] length of stay after randomization of 11.5 [6.3-30.5] days in the ganciclovir group and $18.5[7.5-34.5]$ days in the control group $(P=0.46)$.
On day 60, 18 (46\%) ganciclovir recipients and 19 (51\%) controls had died or were still on mechanical ventilation $(P=0.65)$. The median [IQR] duration of mechanical ventilation after randomization was 12 [6-29] days for all patients from the ganciclovir group and 20 [7-40] days for controls $(P=0.25)$ (Fig. 2b). The median [IQR] duration of mechanical ventilation for day 60 survivors was 12 [5-29] days after randomization for ganciclovir recipients and $22[7-55.5]$ days for controls $(P=0.31)$. Other secondary endpoints (Table 3 ) did not differ between groups. There was no difference between the two groups regarding either the incidence or the microorganisms causing bacteremia/fungemia and ventilator-associated pneumonia diagnosed after inclusion (Table 3 and in the Additional file 3: Tables S1 \& S2). An active CMV infection was diagnosed in 5 patients from the placebo group (after a median of 14 days from inclusion and a range from 3 to 29 days) and in one patient from the ganciclovir group (diagnosed 3 days after inclusion). Study treatment 
Table 3 Outcomes

\begin{tabular}{lll}
\hline Parameters & Placebo group $(\boldsymbol{N}=\mathbf{3 7})$ & Ganciclovir group $(\boldsymbol{N}=\mathbf{3 9 )}$ \\
\hline $\begin{array}{l}\text { Primary outcome } \\
\text { Ventilator-free days on day 60 }\end{array}$ & $0(0-43)$ & $10(0-51)$ \\
Secondary outcomes (post-randomization) & & \\
Day-60 mortality, no. (\%) & $16(43.2)$ & $16(41.0)$ \\
Duration of MV & $20(7-40)$ & $12(6-29)$ \\
ICU length of stay (from admission) & $44.0(21.0-66.5)$ & $36.0(24.0-51.0)$ \\
ICU length of stay (from randomization) & $26.0(11.0-50.0)$ & $17.0(8.0-34.0)$ \\
Hospitalization length (from admission) & $60.0(33.0-75.5)$ & $65.0(28.0-78.0)$ \\
Hospitalization length (from randomization) & $42.0(18.5-60.0)$ & $38.0(13.0-60.0)$ \\
HSV bronchopneumonitis, no. (\%) & $1(2.7)$ & $0(0)$ \\
Cytomegalovirus infection, no. (\%) & $5(13.5)$ & $1(2.6)$ \\
Ventilator-associated pneumonia, no. (\%) & $15(40.5)$ & $13(33.3)$ \\
Secondary bacteremia or fungemia, no. (\%) & $8(21.6)$ & $7(17.9)$ \\
ARDS post-randomization, no. (\%) & $6(16.2)$ & $6(15.4)$ \\
Mild & 0 & 0 \\
Moderate & 3 & 3 \\
Severe & 3 & 3 \\
Septic shock post-randomization, no. (\%) & $14(37.8)$ & $13(33.3)$ \\
Renal replacement therapy until day 28, no. (\%) & $18(48.6)$ & $16(41.0)$ \\
Number of days with study drug, no. (\%) & $14(7.5-14)$ & $14(6.0-14)$ \\
\hline
\end{tabular}

Results are expressed as median (IQR) unless stated otherwise

MV denotes mechanical ventilation, $\mathrm{HSV}$ herpes simplex virus, ARDS acute respiratory distress syndrome, $\mathrm{PaO}_{2} / \mathrm{FiO}_{2}$ partial oxygen pressure in arterial blood/fraction of inspired oxygen ratio, PEEP positive end-expiratory pressure, CPAP continuous positive airway pressure

a The Berlin definition of ARDS is as follows: mild: $\mathrm{PaO}_{2} / \mathrm{FiO}_{2}>200$ but $\leq 300$, with PEEP or CPAP $\geq 5 \mathrm{~cm} \mathrm{H}_{2} \mathrm{O} ; \mathrm{moderate}^{\mathrm{PaO}} / 2 / \mathrm{FiO}{ }_{2}>100$ but $\leq 200$, with PEEP or $\geq 5 \mathrm{~cm}$ $\mathrm{H}_{2} \mathrm{O}$; severe: $\mathrm{PaO}_{2} / \mathrm{FiO}_{2} \leq 100$ with $\mathrm{PEEP} \geq 5 \mathrm{~cm} \mathrm{H}_{2} \mathrm{O}^{20}$

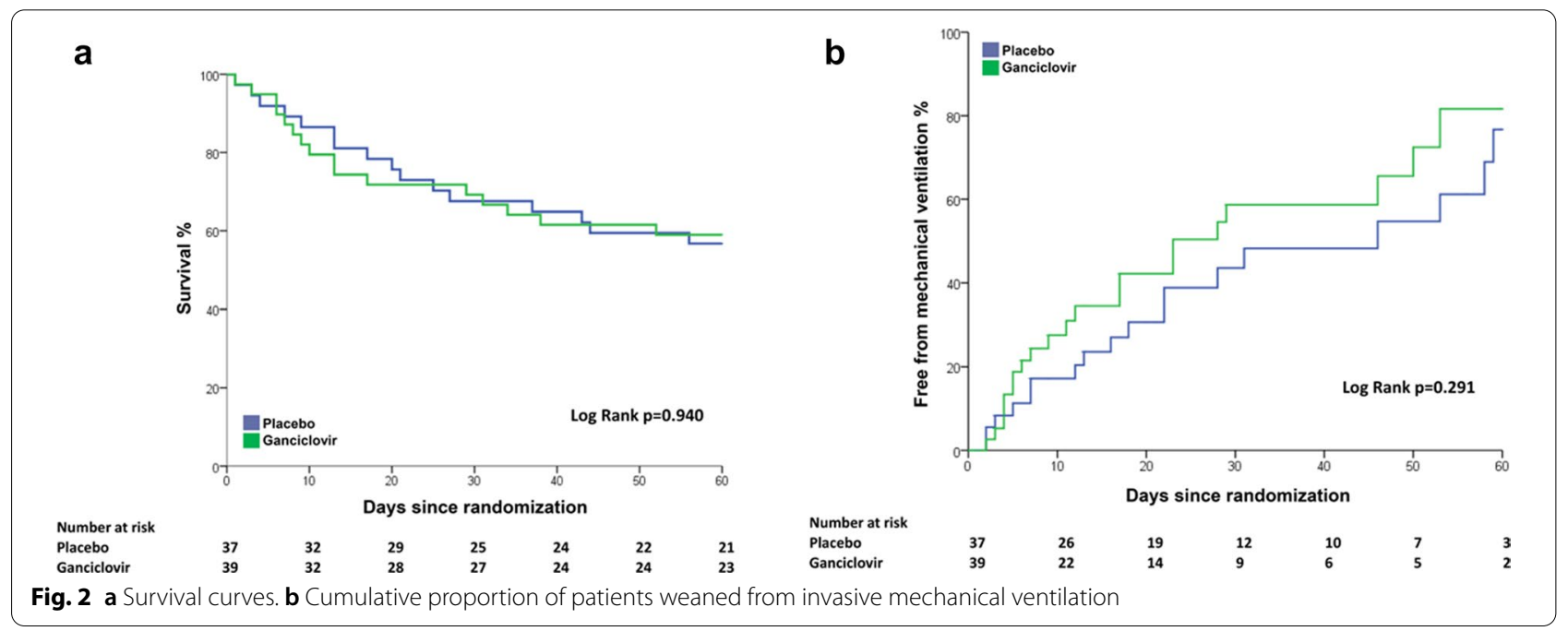

was stopped in 3 of 5 patients receiving placebo and in the patient from the ganciclovir group. These 4 patients were subsequently treated with open-labeled ganciclovir. Patients' clinical courses, as assessed by temperature, white blood-cell count, platelet count, serum creatinine, radiologic score and modified clinical pulmonary infection score from randomization to day 14 as well as by SOFA score and partial oxygen pressure in arterial blood/fraction of inspired oxygen $(\mathrm{PaO} 2 / \mathrm{FiO} 2)$ ratio kinetics from randomization to day 28 were also comparable for the two study groups (see Fig. $3 \mathrm{a}$ and $\mathrm{b}$ and in the Additional file 3: Figs. S1-S6). 

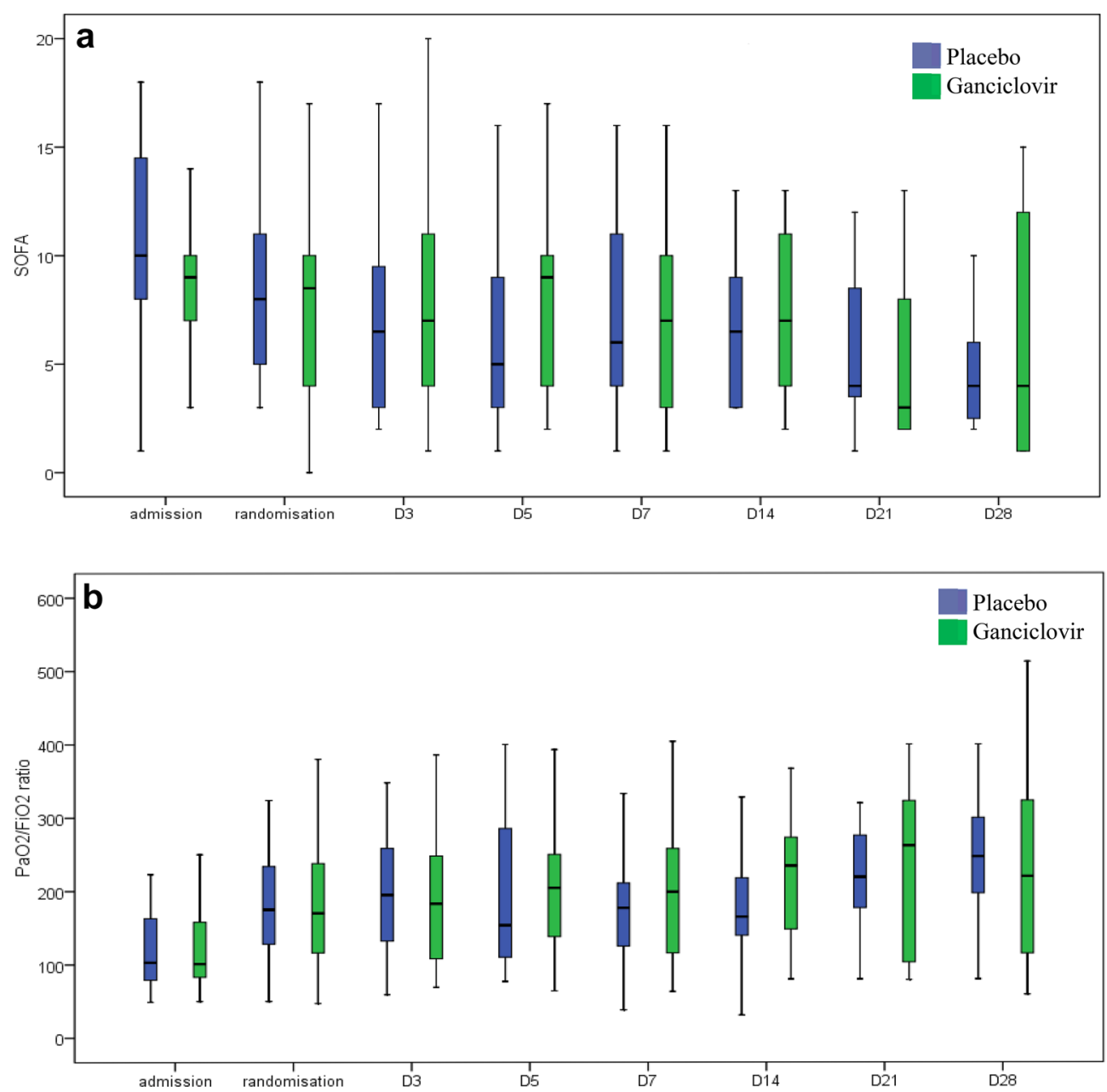

Fig. 3 a Kinetics of the Sequential Organ-Failure Assessment (SOFA) score from Randomization to Day 28 According to Study Group. b Evolution of $\mathrm{PaO} 2 / \mathrm{FiO} 2$ ratio from Randomization to Day 28 According to Study Group. PaO2/FiO2 denotes partial oxygen pressure in arterial blood/fraction of inspired oxygen ratio

\section{Safety}

The adverse event rates were comparable for the two groups: $48.7 \%$ for ganciclovir-treated patients and $48.6 \%$ placebo recipients. No leucopenia or thrombocytopenia was reported. Only one patient (from the ganciclovir group) experienced renal failure requiring renal replacement therapy. Cardiac arrest related to a torsade de pointe was identified in the ganciclovir group. Creatinine levels, white blood cells counts and platelet counts from randomization to day 14 did not differ significantly between the two groups (see in the Additional file 3: Figs. S2-S4), and the percentages of patients requiring renal replacement therapy from randomization to the end of treatment were similar (Table 3).

\section{Discussion}

The results of this study, designed to assess the efficacy of preemptive ganciclovir for CMV reactivation in non-immunosuppressed mechanically ventilated ICU patients, show that this strategy was unable to significantly increase the number of ventilator-free days at day 60.

The incidence of CMV infection in non-immunocompromised ICU patients has been assessed in many studies and analyzed in meta-analyses [4, 30-34]. In seropositive patients monitored three times a week using quantitative plasma CMV PCR and presenting with a large variety of critical illnesses, such as sepsis, cardiac failure, burns and trauma, one-third of these patients presented with positive 
viremia, and the median time to the first detection of viremia was 12 days, with a range of 3 to 57 days [33]. The effects of CMV reactivation on ICU mortality and duration of mechanical ventilation are a matter of debate. In ARDS patients presenting with septic shock, an association has been found between CMV serological status and the number of ventilator-free days to day 28 [35]. Other epidemiological studies and some meta-analyses have looked more specifically at the effects of CMV infection on mortality. In particular, some recent meta-analyses have suggested that there is a strong relationship between the presence of an active CMV infection and mortality, with an odds ratio of approximately 2 [4, 30-32, 34]. In a matched cohort study [11], in which patients were matched on age, gender, SAPS II score and reason for admission, ICU mortality was higher in patients presenting with positive antigenemia $(50 \%)$ compared with control patients $(28 \%, P<0.02)$. Increased mortality at day 60 related to $\mathrm{CMV}$ infection has also been reported in non-immunocompromised ICU patients ( $55 \%$ vs. $20 \%, P=0.01)$ [30]. However, in a series of 86 patients who presented with severe sepsis, although reporting a longer duration of ICU and hospital stays and a prolonged duration of mechanical ventilation when active CMV infection was diagnosed, the authors did not report any increase in mortality related to CMV [36]. We compiled the two randomized controlled trials evaluating prophylactic ganciclovir/valganciclovir $[14,15]$ and the present one evaluating ganciclovir as preemptive therapy. As shown in Additional file 3: Figure S7, these meta-analyses did not show any efficacy of ganciclovir/valganciclovir in decreasing neither mortality at day 28 nor hospital mortality. In contrast, there was a beneficial effect of ganciclovir/valganciclovir in increasing the number of ventilator-free days at day 28 (Additional file 3: Fig. S7).

While prophylactic ganciclovir was associated with a statistically significant increase in ventilator-free days, Limaye et al. did not identify any significant differences between ganciclovir and placebo overall mortality, secondary bacteremia or fungemia, or ICU or hospital length of stay [15]. In this latter study [15], there was a high rate of local lung CMV reactivation in the placebo group and a significant reduction in lung viral load in the ganciclovir group, suggesting that the attenuation of CMV-mediated lung injury is a potential mechanism to explain the significant increase in ventilator-free days among patients in the ganciclovir group and a reduction in the duration of mechanical ventilation days among the group of patients who survived for at least 28 days [15]. As in the present study, it is unlikely that the increase in the number of VFDs was related to a reduced incidence of bacterial/fungal infections. The objective of increasing the number of VFDs by 8 days was probably adequate, as suggested by a recent report in which the mean difference in mechanical ventilation days was increased by 9 days between patients with and without CMV infection [4]. When analysis was restricted to CMV detection in blood, there was still a statistically significant difference in the length of mechanical ventilation, which was 7 days between patients with CMV infection and patients without infection [4]. Interestingly, CMV blood reactivation was not associated with higher mortality, which is consistent with the present study [4].

The assessment of ganciclovir safety in the present study did not permit the identification of any increase in myelotoxicity and renal insufficiency, which is in agreement with recent reports [14, 15].

There were several strengths of the study, including the placebo-controlled, double-blind, multicenter study design; the use of quantitative DNAemia as an inclusion criterion; and the inclusion of objective and clinically relevant outcomes.

\section{Limitations}

This study has several limitations. First, it was stopped prematurely. However, based on the study results, more than 800 patients would have been necessary to show a significant difference in VFD. Second, we used biweekly DNAemia analyses with an arbitrary threshold to characterize reactivation. It is highly probable that a screening test including tracheobronchial specimens for DNA identification would have been more sensitive. Indeed, it has been shown that lung reactivation occurs earlier than reactivation in the blood (median, 14 and 24 days, respectively) [36]. Third, we used VFDs as the main outcome and not mortality or duration of mechanical ventilation. The use of VFDs as a clinical endpoint is recommended in ICU trial design guidelines, especially when the expected difference would involve the mechanical ventilation duration $[24,37,38]$, which was clearly expected. Fourth, we used ganciclovir to treat CMV reactivations. When the study was designed, this was the drug of choice for treating all CMV diseases. There are now several potent, well-tolerated, and newer CMV-active antiviral drugs that could also be considered for future studies done in ICU patients [39, 40]. Fifth, it could be questioned whether preemptive therapy, as chosen in this study, is preferable to a prophylactic strategy. Prophylaxis would be theoretically more attractive because it prevents viral reactivation with its related subsequent direct or indirect damage. Prophylaxis exposes patients to the increased risk of adverse effects, whereas treatment following reactivation minimizes the population's exposure to drug side effects and drug interactions and may decrease pharmaceutical costs. 


\section{Conclusion}

In ICU patients mechanically ventilated for $\geq 96 \mathrm{~h}$ with CMV reactivation in blood, preemptive ganciclovir did not increase the number of ventilator-free days at day 60 . Further studies are needed that could be based on the difference in VFD60 observed in the present study to calculate the number of patients to treat. These studies would require to include more than 800 patients with CMV reactivation, which is a very striving target to reach.

\section{Supplementary Information}

The online version contains supplementary material available at https://doi. org/10.1186/s13613-020-00793-2.

\section{Additional file 1. Protocol. \\ Additional file 2. Statistical analysis plan.}

Additional file 3: Table S1. Microorganisms Responsible for Bacteremia/ Fungemia Post-Randomization According to Study Group. Table S2. Microorganisms other than viruses Responsible for Ventilator-Associated Pneumonia Post-Randomization According to Study Group. Figure S1. Temperature Kinetics from Randomization to Day 14 According to Study Group. Figure S2. White Blood-Cell-Count Kinetics from Randomization to Day 14 according to Study Group. Figure S3. Platelet-Count Kinetics from Randomization to Day 14 According to Study Group. Figure S4. Creatinine-Level Kinetics from Randomization to Day 14 According to Study Group. Figure S5. Kinetics of Radiologic Score 1 from Randomization to Day 14 According to Study Group. Figure S6. Evolution of Modified Clinical Pulmonary Infection Score (mCPIS) 2 from Randomization to Day 14 According to Study Group. Figure S7. Metanalyses from randomized clinical trials evaluating the effects of prophylactic or preemptive ganciclovir/ valganciclovir on mortality at day 28 , hospital mortality and ventilator-free days at day 28 (VFD28)

\section{Abbreviations}

CMV: Cytomegalovirus; ICU: Intensive care unit; HSV: Herpesvirus simplex; PCR: Polymerase chain reaction; SAPS II: Simplified Acute Physiology Score II; SOFA: Sequential Organ Failure Assessment score; VFD60: Ventilator-free days at day 60; ARDS: Acute respiratory distress syndrome; DSMB: Data Safety Monitoring Board; SHR: Subdistribution hazard ratio; 95\% Cl: 95\% Confidence interval; IQR: Interquartile range; SD: Standard deviation; NYHA: New York Heart Association; COPD: Chronic obstructive pulmonary disease; MV: Mechanical ventilation; ECMO: Extracorporeal membrane oxygenation; $\mathrm{PaO}_{2} / \mathrm{FiO}_{2}$ : Partial oxygen pressure in arterial blood/fraction of inspired oxygen ratio; PEEP: Positive endexpiratory pressure; CPAP: Continuous positive airway pressure.

\section{Acknowledgements}

The authors thank Jean-Marie Chrétien and Lucie Van Eeckhoutte for their help in the data management; Camille Pinglis, Céline Sanz and Sabine Valera for their help in data acquisition; Patrick Sudour and Séverine Le Roux for their administrative support. This manuscript was edited for proper English language, grammar, punctuation, spelling, and overall style by American Journal Experts (FBC7-532D-97CC-9B31-5618).

\section{List of contributors}

Members of the Preemptive Herpesviridae Treatment Study Group according to hospital: Hôpital Nord, Marseille, APHM: Médecine Intensive Réanimation: Drs Hraiech, Guervilly, Forel, Roch, Papazian; Mrs Pinglis, Sanz, Valera (RN); Service d'Anesthésie-Réanimation: Drs Leone, Duclos, Hammad, Mathieu, Meresse, Zieleskiewicz.

CHU de Montpellier, Hôpital St-Eloi: Réanimation Chirurgicale: Drs Coisel, Chanques, Jaber; Virologie: Drs Segondy, Foulogne, Montes.

CHU de Clermont-Ferrand: Département de médecine périopératoire, CHU de Clermont-Ferrand: Drs Constantin, Cayot-Constantin, Jabaudon, Godet; Virologie: Drs Brebion, Henquell, Peigue-Lafeuille.
Hôpital Européen Georges-Pompidou, APHP, Paris: Médecine Intensive Réanimation: Drs Aissaoui, Guerot, Diehl, Fagon; Virologie: Drs Bélec, Si-Mohamed.

CHU de Montpellier, Hôpital Lapeyronie: Médecine Intensive Réanimation, Université de Montpellier: Drs Jung, Klouche, Platon, Brunot, Daubin, Corrne. Mrs Gniadek (RN).

CHU de Clermont-Ferrand: Réanimation Médicale, Hôpital Gabriel-Montpied: Drs Coupez, Souweine.

CHU de Grenoble: Médecine Intensive Réanimation: Drs Schwebel, Terzi; Virologie: Dr Morand.

Hôpital Timone, APHM, Marseille: Réanimation des Urgences: Drs

Bourenne, Gainnier, Dr Carvelli; Virologie: Drs Zandotti, Charrel.

Hôpital Européen, Marseille: Réanimation: Drs Allardet-Servent, Signouret; Virologie: Drs Khiri, Halfon.

Centre Hospitalier Régional, Orléans, Médecine Intensive Réanimation: Drs Boulain, Kamel, Mathonnet, Barbier, Jacquier, Muller, Benzekri-Lefevre, Nay, Runge, Skarzynski; Virologie: Dr Guigon.

Hôpitaux Universitaires Pitié Salpêtrière-Charles Foix, APHP, Paris: Médecine Intensive Réanimation: Drs Hékimian, Bréchot, Nieszkowska, Schmidt, Combes, Chastre, Luyt; Réanimation Chirurgicale Polyvalente, Département d'Anesthésie Réanimation: Drs Lu, Arbelot, Vezinet, Monsel, Rouby; Virologie: Drs Burrel, Boutolleau.

Hôpital Bichat, APHP, Paris: Médecine Intensive Réanimation: Drs Sonneville, Timsit; Virologie: Drs Houhou, Brun-Vezinet.

Hôpital Cochin, APHP, Paris: Médecine Intensive Réanimation: Drs Cariou, Charpentier, Pene, Mira; Virologie: Dr Rozenberg.

Hospices Civils de Lyon, Hôpital Edouard-Herriot: Réanimation Chirurgicale: Dr Rimmelé; Virologie: Drs Frobert, Billaud, Lina.

CHU de Limoges Dupuytren: Réanimation Polyvalente: Drs Clavel, François, Vignon; Virologie: Drs Alain, Hant.

CHU de Nantes. Réanimation chirurgicale: Drs Asehnoune, Roquilly, Hourma. Médecine Intensive Réanimation: Drs Reignier, Garret. Virologie: Dr Bressollette.

\section{Authors' contributions}

LP: study design, analysis, drafting of the manuscript, accountable for all aspects of the work. SJ: study design, acquisition, analysis, manuscript revision, final approval. SH: acquisition, manuscript revision, final approval. KB: study design, analysis, manuscript revision, final approval. SCC: acquisition, final approval. NA: acquisition, final approval. BJ: acquisition, final approval. Marc Leone: acquisition, final approval. BS: acquisition, final approval. CS: acquisition, final approval. JB: acquisition, final approval. JAS: acquisition, final approval. TK: acquisition, final approval. QL: acquisition, final approval. CZ: design, final approval. AL: analysis. CP-R: design, final approval. JC: design, final approval. J-MF: design, acquisition, final approval. C-EL: study design, acquisition, analysis, manuscript revision, final approval. All authors read and approved the final manuscript.

\section{End notes}

Not applicable.

\section{Funding}

The study was funded by the Direction de la Recherche en Santé and the French Ministry of Health; Programme Hospitalier de Recherche Clinique 2011.

\section{Availability of data and materials}

The datasets used and/or analyzed during the current study are available from the corresponding author on reasonable request.

\section{Ethics approval and consent to participate}

An independent Ethics Committee (Comité de Protection des Personnes Sud Méditerranée 5) and the Agence Nationale de Sécurité du Médicament et des Produits de Santé approved the protocol and the amendments.

\section{Consent for publication}

Not applicable.

\section{Competing interests}

No potential conflict of interest relevant to this article was reported. The following conflicts of interest are outside the area of the article. Dr Papazian 
reports receiving lecture fees from Hamilton. Dr Jaber reports receiving consulting fees from Dräger, Fisher-Paykel, Xenios-Fresenius Medical and Medtronic. Dr Aissaoui reports receiving lecture fees from Astra-Zeneca and Thoratec. Dr Lu reports receiving lectures fees from Aerogen. Dr Chastre reports receiving lecture and consulting fees from Bayer Healthcare, Pfizer, Merck Sharp \& Dohme, Aridis, the Medicines Company, Astra Zeneca, Tigenix Accelerate Diagnotics, Inotrem and Glaxo Smith Kline. Dr Luyt reports receiving lecture fees from ThermoFisher Brahms, Biomérieux, Merck Sharp \& Dohme and Aerogen, and consulting fees from Bayer Healthcare, Carmat and Faron. Dr Leone reports receiving fees for lectures from MSD, Pfizer, Octapharma, 3M, Biomérieux and for consulting from Amomed, Aguettant and Gilead. Dr Chastre has received honoraria for lectures, or for participating in advisory boards, from Accelerate Diagnostics, AstraZeneca/Medimmune, Bayer, Cubist/Merck, GSK, Inotrem, Kenta/Aridis, Shionogi and Tigenix.

\section{Author details}

${ }^{1}$ Médecine Intensive Réanimation, Aix-Marseille Université, Hôpital Nord, Chemin des Bourrely, 13015 Marseille, France. ${ }^{2}$ Réanimation Chirurgicale, Centre Hospitalier Universitaire de Montpellier, Hôpital St-Eloi, Montpellier, France. ${ }^{3}$ Laboratoire de Santé Publique, Aix-Marseille Université, Assistance Publique-Hôpitaux de Marseille, Marseille, France. ${ }^{4}$ Département de Médecine Periopératoire, CHU Clermont-Ferrand, Clermont-Ferrand, France. ${ }^{5}$ Médecine Intensive Réanimation, Hôpital Européen Georges-Pompidou, APHP, Paris, France. ${ }^{6}$ Médecine Intensive Réanimation, Centre Hospitalier Universitaire de Montpellier, Hôpital Lapeyronie, Montpellier, France. ${ }^{7}$ Service d'Anesthésie-Réanimation, Aix-Marseille Université, Hôpital Nord, Assistance Publique-Hôpitaux de Marseille, Marseille, France. ${ }^{8}$ Réanimation Médicale, CHU Gabriel-Montpied, Clermont-Ferrand, France. ${ }^{9}$ Médecine Intensive Réanimation, CHU Grenoble Alpes, La Tronche, France. ${ }^{10}$ Réanimation des Urgences et Médicale, Aix-Marseille Université, Hôpital Timone, APHM, Marseille, France. ${ }^{11}$ Réanimation, Hôpital Européen, Marseille, France. ${ }^{12}$ Médecine Intensive Réanimation, Centre Hospitalier Régional, Orléans, France. ${ }^{13}$ Réanimation Chirurgicale Polyvalente, Département d'Anesthésie-Réanimation, Hôpitaux Universitaires Pitié Salpêtrière-Charles Foix, APHP, Paris, France. ${ }^{14}$ Laboratoire de Virologie, IHU Méditerranée Infection, CHU Timone UMR190-Emergence des Pathologies Virales, Marseille, France. ${ }^{15}$ Pharmacie, Hôpitaux Sud, APHM, Marseille, France. ${ }^{16}$ Sorbonne Université, INSERM, Médecine Intensive Réanimation, Institut de Cardiologie, Hôpitaux Universitaires Pitié SalpêtrièreCharles Foix, Assistance Publique-Hôpitaux de Paris, Paris, France.

Received: 30 September 2020 Accepted: 18 December 2020 Published online: 11 February 2021

\section{References}

1. Chiche L, Forel JM, Papazian L. The role of viruses in nosocomial pneumonia. Curr Opin Infect Dis. 2011;24(2):152-6.

2. Gkrania-Klotsas E, Langenberg C, Sharp SJ, Luben R, Khaw KT, Wareham NJ. Higher immunoglobulin $\mathrm{G}$ antibody levels against cytomegalovirus are associated with incident ischemic heart disease in the populationbased EPIC-Norfolk cohort. J Infect Dis. 2012;206(12):1897-903.

3. Papazian L, Hraiech S, Lehingue S, Roch A, Chiche L, Wiramus S, et al. Cytomegalovirus reactivation in ICU patients. Intensive Care Med. 2016;42(1):28-37.

4. Li X, Huang Y, Xu Z, Zhang R, Liu X, Li Y, et al. Cytomegalovirus infection and outcome in immunocompetent patients in the intensive care unit: a systematic review and meta-analysis. BMC Infect Dis. 2018;18(1):289.

5. Barry SM, Johnson MA, Janossy G. Cytopathology or immunopathology? The puzzle of cytomegalovirus pneumonitis revisited. Bone Marrow Transplant. 2000;26(6):591-7.

6. Papazian L, Fraisse A, Garbe L, Zandotti C, Thomas P, Saux P, et al. Cytomegalovirus. An unexpected cause of ventilator-associated pneumonia. Anesthesiology. 1996;84(2):280-7.

7. Papazian L, Thomas P, Bregeon F, Garbe L, Zandotti C, Saux P, et al. Open-lung biopsy in patients with acute respiratory distress syndrome. Anesthesiology. 1998;88(4):935-44.

8. Grundy JE, Shanley JD, Griffiths PD. Is cytomegalovirus interstitial pneumonitis in transplant recipients an immunopathological condition? Lancet. 1987;2(8566):996-9.
9. Chiche L, Forel JM, Roch A, Guervilly C, Pauly V, Allardet-Servent J, et al. Active cytomegalovirus infection is common in mechanically ventilated medical intensive care unit patients. Crit Care Med. 2009;37(6):1850-7.

10. Cook CH, Martin LC, Yenchar JK, Lahm MC, McGuinness B, Davies EA, et al. Occult herpes family viral infections are endemic in critically ill surgical patients. Crit Care Med. 2003;31(7):1923-9.

11. Jaber S, Chanques G, Borry J, Souche B, Verdier R, Perrigault PF, et al. Cytomegalovirus infection in critically ill patients: associated factors and consequences. Chest. 2005:127(1):233-41.

12. Walton AH, Muenzer JT, Rasche D, Boomer JS, Sato B, Brownstein BH, et al. Reactivation of multiple viruses in patients with sepsis. PLOS ONE. 2014;9(2):e98819.

13. Cook CH, Trgovcich J, Zimmerman PD, Zhang Y, Sedmak DD. Lipopolysaccharide, tumor necrosis factor alpha, or interleukin-1 beta triggers reactivation of latent cytomegalovirus in immunocompetent mice. J Virol. 2006;80(18):9151-8

14. Cowley NJ, Owen A, Shiels SC, Millar J, Woolley R, Ives N, et al. Safety and efficacy of antiviral therapy for prevention of cytomegalovirus reactivation in immunocompetent critically ill patients: a randomized clinical trial. JAMA Internal Med. 2017;177(6):774-83.

15. Limaye AP, Stapleton RD, Peng L, Gunn SR, Kimball LE, Hyzy R, et al. Effect of ganciclovir on IL-6 levels among cytomegalovirus-seropositive adults with critical illness: a randomized clinical trial. JAMA. 2017;318(8):731-40.

16. Luyt CE, Forel JM, Hajage D, Jaber S, Cayot-Constantin S, Rimmele T, et al. Acyclovir for mechanically ventilated patients with herpes simplex virus oropharyngeal reactivation: a randomized clinical trial. JAMA Internal Med. 2019.

17. Fryer JF, Heath $A B$, Anderson $R$, Minor PD, World Health Organization. Biologicals U, Collaborative Study G, et al. Collaborative study to evaluate the proposed 1st [first] WHO international standard for human cytomegalovirus (HCMV) for nucleic acid amplification (NAT)-based assays/by Jacqueline F. Fryer, Alan B. Heath, Rob Anderson, Philip D. Minor and the Collaborative Study Group. Geneva: World Health Organization; 2010.

18. Vincent JL, Moreno R, Takala J, Willatts S, De Mendonca A, Bruining $\mathrm{H}$, et al. The SOFA (Sepsis-related Organ Failure Assessment) score to describe organ dysfunction/failure. On behalf of the Working Group on Sepsis-Related Problems of the European Society of Intensive Care Medicine. Intensive Care Med. 1996;22(7):707-10.

19. Schoenfeld DA, Bernard GR, Network A. Statistical evaluation of ventilator-free days as an efficacy measure in clinical trials of treatments for acute respiratory distress syndrome. Crit Care Med. 2002;30(8):1772-7.

20. Luyt CE, Combes A, Deback C, Aubriot-Lorton MH, Nieszkowska A, Trouillet $\mathrm{JL}$, et al. Herpes simplex virus lung infection in patients undergoing prolonged mechanical ventilation. Am J Respir Crit Care Med. 2007:175(9):935-42

21. Fine JP, Gray RJ. A proportional hazards model for the subdistribution of a competing risk. J Am Stat Assoc. 1999;94(446):496-509.

22. Beitler JR, Sarge T, Banner-Goodspeed VM, Gong MN, Cook D, Novack V, et al. Effect of Titrating Positive End-Expiratory Pressure (PEEP) with an esophageal pressure-guided strategy vs an empirical high PEEP-Fio2 strategy on death and days free from mechanical ventilation among patients with acute respiratory distress syndrome: a randomized clinical trial. JAMA. 2019;321(9):846-57.

23. Finkelstein DM, Schoenfeld DA. Combining mortality and longitudinal measures in clinical trials. Stat Med. 1999;18(11):1341-54.

24. Novack V, Beitler JR, Yitshak-Sade M, Thompson BT, Schoenfeld DA, Rubenfeld $\mathrm{G}$, et al. Alive and ventilator free: a hierarchical, composite outcome for clinical trials in the acute respiratory distress syndrome. Crit Care Med. 2020;48(2):158-66.

25. Luo D, Wan X, Liu J, Tong T. Optimally estimating the sample mean from the sample size, median, mid-range, and/or mid-quartile range. Stat Methods Med Res. 2018;27(6):1785-805

26. Wan X, Wang W, Liu J, Tong T. Estimating the sample mean and standard deviation from the sample size, median, range and/or interquartile range. BMC Med Res Methodol. 2014;14:135.

27. Mantel N, Haenszel W. Statistical aspects of the analysis of data from retrospective studies of disease. J Natl Cancer Inst. 1959;22(4):719-48.

28. DerSimonian R, Laird N. Meta-analysis in clinical trials. Control Clin Trials. 1986;7(3):177-88.

29. Higgins JP, Thompson SG, Deeks JJ, Altman DG. Measuring inconsistency in meta-analyses. BMJ. 2003;327(7414):557-60. 
30. Coisel Y, Bousbia S, Forel JM, Hraiech S, Lascola B, Roch A, et al. Cytomegalovirus and herpes simplex virus effect on the prognosis of mechanically ventilated patients suspected to have ventilator-associated pneumonia. PLOS ONE. 2012;7(12):e51340.

31. Kalil AC, Florescu DF. Prevalence and mortality associated with cytomegalovirus infection in nonimmunosuppressed patients in the intensive care unit. Crit Care Med. 2009:37(8):2350-8.

32. Kalil AC, Florescu DF. Is cytomegalovirus reactivation increasing the mortality of patients with severe sepsis? Crit Care. 2011;15(2):138.

33. Limaye AP, Kirby KA, Rubenfeld GD, Leisenring WM, Bulger EM, Neff MJ, et al. Cytomegalovirus reactivation in critically ill immunocompetent patients. JAMA. 2008;300(4):413-22.

34. Lachance P, Chen J, Featherstone R, SligI WI. Association between cytomegalovirus reactivation and clinical outcomes in immunocompetent critically ill patients: a systematic review and meta-analysis. Open Forum Infect Dis. 2017;4(2):ofx029.

35. Ong DS, Klein Klouwenberg PM, Verduyn Lunel FM, Spitoni C, Frencken JF, Dekker HA, et al. Cytomegalovirus seroprevalence as a risk factor for poor outcome in acute respiratory distress syndrome*. Crit Care Med. 2015;43(2):394-400

36. Heininger A, Haeberle H, Fischer I, Beck R, Riessen R, Rohde F, et al. Cytomegalovirus reactivation and associated outcome of critically ill patients with severe sepsis. Crit Care. 2011;15(2):R77.
37. Young P, Hodgson C, Dulhunty J, Saxena M, Bailey M, Bellomo R, et al. End points for phase II trials in intensive care: recommendations from the Australian and New Zealand Clinical Trials Group consensus panel meeting. Crit Care Resuscitation. 2012;14(3):211-5.

38. Yehya N, Harhay MO, Curley MAQ, Schoenfeld DA, Reeder RW. Reappraisal of ventilator-free days in critical care research. Am J Respir Crit Care Med. 2019;200(7):828-36.

39. Acosta E, Bowlin T, Brooks J, Chiang L, Hussein I, Kimberlin D, et al. Advances in the development of therapeutics for cytomegalovirus infections. J Infect Dis. 2020;221(Supplement_1):S32-s44.

40. Marty FM, Ljungman P, Chemaly RF, Maertens J, Dadwal SS, Duarte RF, et al. Letermovir prophylaxis for cytomegalovirus in hematopoietic-cell transplantation. N Engl J Med. 2017;377(25):2433-44.

\section{Publisher's Note}

Springer Nature remains neutral with regard to jurisdictional claims in published maps and institutional affiliations.

\section{Submit your manuscript to a SpringerOpen ${ }^{\circ}$ journal and benefit from:}

- Convenient online submission

- Rigorous peer review

- Open access: articles freely available online

- High visibility within the field

- Retaining the copyright to your article

Submit your next manuscript at $\boldsymbol{\nabla}$ springeropen.com 